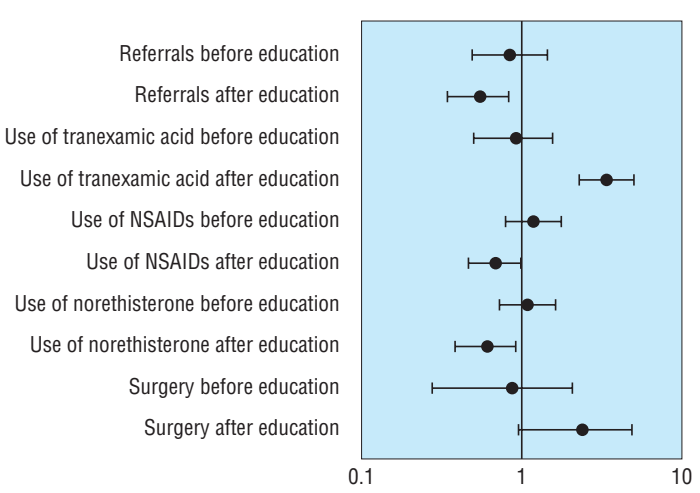

NSAID = non-steroidal anti-inflammatory drug

Odds ratios for various aspects of menorrhagia management both before and after educational intervention. Bars represent 95\% confidence intervals

tranexamic acid ( $3.36 ; 2.21$ to 4.96$)$, and a reduction in norethisterone treatment $(0.67 ; 0.46$ to 0.95$)$ for cases of menorrhagia. Non-steroidal anti-inflammatory drugs were prescribed slightly less commonly in groups receiving intervention $(0.61 ; 0.38$ to 0.90$)$. The odds of hysterectomy in the education group were increased by 2.33 ( 0.94 to 4.87 ). There were no demographic differences between practices.

\section{Comment}

The data show a positive change in behaviour among doctors as a result of education. The results also validate previously reported randomised controlled trial data. ${ }^{3}$ There were no before and after differences in control practices, indicating that external confounders had no effect. The trend towards an increased chance of hysterectomy in intervention groups may be because they had already received appropriate first line treatment. These women may proceed to more appropriate surgery as a result of this intervention.

We thank all general practitioners who participated in the study and the regional postgraduate education office, Anglia and Oxford Health Authority, Fulbourn, Cambridge, without whose assistance it would not have been possible to complete the study.

Contributors: GRKF helped with audit design and implementation, audit management, data collation and analysis, and paper preparation and approval. AP helped with audit design and paper preparation and approval. He is also the guarantor. TG was involved in implementation of the audit, management, data collation and approval. RMN was involved in data collation and analysis and paper preparation and approval. SWD was involved in audit analysis and paper preparation and approval. NED was involved in paper preparation and approval. SKS was involved in paper preparation and approval.

Funding: The project was funded by the NHS Research and Development Health Technology Assessment programme.

Competing interests: None declared.

Vessey M, Villard-MacKintosh L, McPherson K, Coulter A, Yeates D. The epidemiology of hysterectomy: findings of a large cohort study. Br J Obstet Gynaecol 1992:99:402-7.

2 Coulter A, Bradlow J, Agass M, Martin-Bates C, Tulloch A. Outcomes of referrals to gynaecology outpatient clinics for menstrual problems: an audit of general practice records. BrJ Obstet Gynaecol 1991;98:789-96.

3 Fender G, Prentice A, Gorst T, Nixon RM, Duffy SW, Day NE, et al Randomised controlled trial of educational package on management of menorrhagia in primary care: the Anglia menorrhagia education study $B M J 1999 \cdot 318 \cdot 1246-50$

4 Effective Health Care: The management of menorrhagia. York: NHS Centre for Reviews and Dissemination, University of York, 1995 (No. 1).

5 Nixon R, Duffy S, Fender GRK, Prevost T, Day N. Randomisation at the level of practice surgery: use of pre-intervention data and random effects models. Statistics in Med (in press).

(Accepted 15 August 2000)

\title{
Violence by clients towards female prostitutes in different work settings: questionnaire survey
}

\author{
Stephanie Church, Marion Henderson, Marina Barnard, Graham Hart
}

Centre for Drug Misuse Research, Glasgow University, Glasgow G12 8SQ Stephanie Church research fellow Marina Barnard senior research fellow

Medical Research Council Social and Public Health Science Unit, University of Glasgow, Glasgow G12 8RZ

Marion Henderson senior researcher

Graham Hart associate director

Correspondence to: S Church Stephanie@msoc. mrc.gla.ac.uk

BMJ 2001;322:524-5
Violence by clients towards prostitutes has seldom been the focus of public and academic interest, yet it is a major health issue. ${ }^{12}$ Concern has mostly focused on the potential of prostitutes to transmit sexual infections, notably HIV, to their clients and subsequently partners. ${ }^{3}$ Features of female prostitution that have a direct impact on the health of prostitutes but not the health of others have therefore tended to be overlooked. The scant research that is available on violence by clients shows that prostitutes who work outdoors in particular routinely confront clients who are verbally, sexually, and physically violent towards them. ${ }^{4}$ We report on the prevalence of violence by clients against female prostitutes working either outdoors or indoors in three major British cities.

\section{Methods and results}

During 1999 three female researchers (SC, MB, and Catherine Benso) contacted 240 female prostitutes; 115 worked outdoors (40 in Leeds, 75 in Glasgow) and 125 worked indoors in saunas or flats $(50$ in Leeds, 75 in Edinburgh). We designed a structured questionnaire using previously validated measures to record personal characteristics, working patterns, drug and alcohol use (in the past six months), type and frequency of violence by clients (ever or in the past six months), and levels of attack reported to police. We contacted $156(65 \%)$ prostitutes in their place of work and $84(35 \%)$ through drop-in centres. We used SPSS to test for significance, and multivariate binary logistic regression analysis to identify variables most strongly associated with violence experienced ever or in the past six months.

The table shows that prostitutes working outdoors were younger, involved in prostitution at an earlier age, reported more illegal drug use, and experienced significantly more violence from their clients than those working indoors (81\% (93 of 115) v 48\% (60 of $\left.125), \chi^{2}=29.2, \mathrm{df}=1, \mathrm{P}<0.0001\right)$. Prostitutes working outdoors most frequently reported being slapped, punched, or kicked, whereas prostitutes working 
Personal characteristics, drug use, and experience of client violence by prostitutes working indoors or outdoors. Values are numbers (percentages) of prostitutes unless stated otherwise

\begin{tabular}{lccc} 
& \multicolumn{2}{c}{ Work setting } & \\
\cline { 2 - 3 } Variable & $\begin{array}{c}\text { Outdoors } \\
\text { (n=115) }\end{array}$ & $\begin{array}{c}\text { Indoors } \\
\text { (n=125) }\end{array}$ & P \\
\hline value \\
\hline Mean (SD) age & $25.7(6.7)$ & $28.4(6.9)$ & 0.002 \\
\hline Mean (SD) age first paid for sex & $19.6(5.1)$ & $22.7(5.9)$ & $<0.001$ \\
\hline Mean (SD) years in prostitution & $4.8(5.0)$ & $4.3(4.9)$ & 0.440 \\
\hline Main reason for prostitution: & & & \\
\hline Household expenses and children & $32(28)$ & $93(74)$ & $<0.001$ \\
\hline To pay for drugs & $72(63)$ & $1(1)$ & $<0.001$ \\
\hline To save up for something & $5(4)$ & $23(18)$ & 0.001 \\
\hline Other & $6(5)$ & $8(6)$ & 0.696 \\
\hline Illegal drug used in past six months & $107(93)$ & $86(69)$ & $<0.001$ \\
\hline Type of illegal drug used: & & & \\
\hline Heroin & $90(78)$ & $6(5)$ & $<0.001$ \\
\hline Other opiate & $45(39)$ & $12(10)$ & $<0.001$ \\
\hline Tranquillisers & $43(37)$ & $99(79)$ & $<0.001$ \\
\hline Crack cocaine & $37(32)$ & $5(4)$ & $<0.001$ \\
\hline Amphetamine & $13(11)$ & $38(30)$ & $<0.001$ \\
\hline Cocaine & $20(17)$ & $19(15)$ & 0.646 \\
\hline Cannabis & $70(61)$ & $62(50)$ & 0.080 \\
\hline Injected drugs in past month & $56(49)$ & $4(3)$ & $<0.001$ \\
\hline Ever experienced client violence & $93(81)$ & $60(48)$ & $<0.001$ \\
\hline Experienced violence in past six months & $58(50)$ & $32(26)$ & $<0.001$ \\
\hline Type of violence ever experienced: & & & \\
\hline Slapped, punched, or kicked & $54(47)$ & $17(14)$ & $<0.001$ \\
\hline Threatened with physical violence & $45(39)$ & $18(14)$ & $<0.001$ \\
\hline Robbery & $42(37)$ & $12(10)$ & $<0.001$ \\
\hline Attempted robbery & $30(26)$ & $6(5)$ & $<0.001$ \\
\hline Beaten & $31(27)$ & $1(1)$ & $<0.001$ \\
\hline Threatened with weapon & $28(24)$ & $8(6)$ & $<0.001$ \\
\hline Held against will & $29(25)$ & $19(15)$ & 0.053 \\
\hline Attempted rape (vaginal or anal) & $32(28)$ & $21(17)$ & 0.040 \\
\hline Strangulation & $23(20)$ & $7(6)$ & 0.001 \\
\hline Kidnapped & $23(20)$ & $3(2)$ & $<0.001$ \\
\hline Forced to give client oral sex & $20(17)$ & $4(3)$ & $<0.001$ \\
\hline Raped (vaginal) & $25(22)$ & $2(2)$ & $<0.001$ \\
\hline Attempted kidnap & $14(12)$ & $1(1)$ & $<0.001$ \\
\hline Slashed or stabbed & $8(7)$ & 0 & 0.003 \\
\hline Raped (anal) & $6(5)$ & $8(6)$ & 0.696 \\
\hline Reported at least one incident of client & $41 / 93(44)$ & $11 / 60(18)$ & $<0.001$ \\
violence to police & & & \\
\hline & & & \\
\hline
\end{tabular}

indoors cited attempted rape. Multiple logistic regression showed that working outdoors rather than indoors was associated with higher levels of violence by clients than was the city, drug use, and duration of, or age that women began, prostitution. Prostitutes working outdoors in Glasgow were six times more likely to have experienced recent violence by clients than those working indoors in Edinburgh. Only 34\% $(52 / 153)$ of prostitutes who had experienced violence by clients reported it to the police, and this was reported more often by prostitutes working outdoors than indoors (44\% (41 of 93) $v 18 \%$ (11 of 60$), \chi^{2}=10.4$, $\mathrm{df}=1, \mathrm{P}<0.0012)$.

\section{Comment}

Half of prostitutes working outdoors and over a quarter of those working indoors reported some form of violence by clients in the past six months. These levels of violence need to be addressed and reported attacks responded to more effectively in terms of service provision, police intervention, and judicial processes. Recognising that violence by clients occurs to women working both indoors and outdoors would be an important step towards preventing or reducing the incidence of violence.

The sexual health of prostitutes is just one element of service need in circumstances where they confront potentially abusive clients. The range and content of comprehensive health services for prostitutes is an area that should be addressed with some urgency if levels of morbidity and mortality from violence by clients is to be reduced.

We thank all the women that participated in the study, the staff of the three outreach services in Glasgow, Edinburgh, and Leeds, and Catherine Benson for her contribution to the design of the questionnaire, data collection, and data entry.

Contributors: SC helped review the literature, helped collect and enter the data, performed the data analysis, formulated conclusions, wrote the first draft of the manuscript, and revised the manuscript. MH performed the data analysis, formulated the conclusions, and helped revise the manuscript. MB had the original idea for the study, helped review the literature, sought ethical approval and funding, helped with data collection, formulated the conclusions, supervised the overall conduct of the project, and helped revise the manuscript. GH had the original idea for the study, supervised the overall conduct of the project, and helped revise the manuscript. MB and GH will act as guarantors for the paper.

Funding: Economic and Social Research Council (L133251025; Violence Research Programme).

Competing interests: None declared.

1 Lowman J, Fraser L. Violence against persons who prostitute: the experience in British Columbia. Vancouver: Simon Fraser University, 1995.

2 Gilchrist G, Taylor A, Goldberg D, Mackie C, Denovan A, Green S. Behavioural and lifestyle study of women using a drop-in centre for female street sex workers in Glasgow, Scotland: a 10-year comparative study. Addict Res (in press).

3 Ward H, Day S, Mezzone J, Dunlop L, Donegan C, Farrar S. Prostitution and risk of HIV: female prostitutes in London. BMJ 1993;307:356-8.

4 McKeganey N, Barnard M. Sex work on the streets, prostitutes and their clients. Buckingham: Open University Press, 1996.

5 Phoenix P. Prostitute identities: men, money and violence. Br J Criminol 1999;40:37-55.

(Accepted 2 November 2000)

\section{Corrections and clarifications}

Lipid concentrations and the use of lipid lowering drugs: evidence from a national cross sectional survey Because of an error on the part of the BMJ, the authors (Paola Primatesta and Neil R Poulter) of this paper (25 November, pp 1322-5) were said to have no competing interests, whereas in fact Professor Poulter has received funds from several pharmaceutical companies to attend symposiums, speak, organise education, consult, and support research and members of staff. Professor Poulter ticked our form to say that he had received this support but then ticked the box to say that he had no competing interests. Our form did not make sufficiently clear that we regard receiving funds for these reasons as being a competing interest. We failed to pick up on the inconsistency in Professor Poulter's form, and we apologise to him for that. We have amended the form, which is on our website at bmj.com/cgi/content/full/317/7154/291/DC1\#aut

\section{Endpiece \\ Freedom of press}

Freedom of press is limited to those who own one.

H L Mencken,

American editor, author, and critic, 1880-1956 